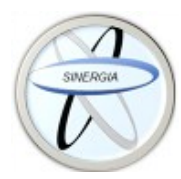

Revista Médica Sinergia

https://doi.org/10.31434/rms.v6i11.734

Vol. 6, Núm. 11, noviembre 2021,

$\underline{\mathrm{e} 734}$

revistamedicasinergia@gmail.com

\title{
Diagnóstico de osteomielitis aguda hematógena en el niño
}

Diagnosis of acute hematogenous osteomyelitis in children

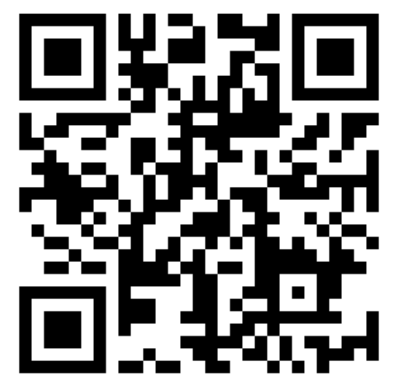

Recibido

$12 / 10 / 2021$
Corregido

$17 / 10 / 2021$
1Dra. Gindreska Paizano Vanega Hospital de Trauma, San José, Costa Rica

(iD) https://orcid.org/0000-0002-9265-820X

${ }^{2}$ Dr. Stuard Chacón Díaz Área de Salud Tilarán, Guanacaste, Costa Rica

(iD) https://orcid.org/0000-0002-2213-5411

${ }^{3}$ Dr. Jairo Sandoval Vargas Hospital México, San José, Costa Rica (i) https://orcid.org/0000-0002-9454-3860

Aceptado 20/10/2021

\section{RESUMEN}

La osteomielitis aguda es una infección ósea causada por la inoculación de microorganismos especialmente por vía hematógena, siendo el Staphylococcus aureus es el agente etiológico más frecuente, suele ser unifocal, afectando frecuentemente a las metáfisis de huesos largos, especialmente fémur, tibia y húmero. La presentación clínica depende del grupo de edad y la etiología. Dentro de las manifestaciones clínicas más importantes se encuentran el dolor localizado y la disminución de movilidad de la extremidad afectada. Para establecer el diagnóstico de osteomielitis son necesarios la sospecha clínica, el examen físico completo, estudios de laboratorio y técnicas de imágenes como son los rayos $\mathrm{X}$, ultrasonido, TAC, RMN y estudios de medicina nuclear.

PALABRAS CLAVE: osteomielitis; niños; infección; hematógena.

\section{ABSTRACT}

Acute osteomyelitis is a bone infection caused by the inoculation of microorganisms, especially hematogenous, Staphylococcus aureus is the most frequent etiological agent. The most important clinical manifestations are localized pain and decreased function. To establish the diagnosis of osteomyelitis, clinical suspicion, complete physical examination, laboratory studies 
and imaging techniques such as X-rays, ultrasound, CT, MRI and nuclear medicine studies are necessary.

KEYWORDS: osteomyelitis, children, infection, hematogenous.

\footnotetext{
${ }^{1}$ Médica general, graduada de la Universidad Latina de Costa Rica (U. Latina). Cód. MED13470. Correo: ginpv@hotmail.com

${ }^{2}$ Médico general, graduado de la Universidad de Ciencias Médicas (UCIMED). Cód. MED16659. Correo: stucd95@gmail.com

${ }^{3}$ Médico general, graduado de la Universidad Autónoma de Centroamérica (UACA). Cód. MED13269. Correo: jairosv1522@gmail.com
}

\section{INTRODUCCIÓN}

La osteomielitis aguda es una infección ósea progresiva que ocasiona destrucción inflamatoria e isquémica de los tejidos esqueléticos, con infarto óseo, formación de hueso reactivo y fistulización (1). Etimológicamente se deriva del griego osteo, que significa hueso, myelós, medula, e itis, inflamación (2).

Desde la antigüedad se ha demostrado que la osteomielitis ha afectado al ser humano, ya que la primera referencia de esta patología fue descrita por Hipócrates, quién propuso que cuando las úlceras continuaban abiertas por un año o más, era necesaria la exfoliación del hueso (2).

En el siglo XVIII Alexander Mackenzie y William Bromfield describieron por primera vez el Síndrome de Osteomielitis Hematógena Aguda. En 1827 Natham Smith demostró que este síndrome ocurre casi exclusivamente en niños y adolescentes. En el año de 1878 Rosenbach confirmo la causa bacteriana de la osteomielitis (3).

Existen múltiples maneras de clasificar la osteomielitis, la forma tradicional es de acuerdo a su duración, en aguda cuando es menor a dos semanas, subaguda de dos semanas a tres meses y crónica cuando es una duración mayor (4). Otra clasificación es la de Waldvogel, descrita en 1970, la cual se basa en la etiología de la enfermedad (5).

La osteomielitis con diseminación vía hematógena es la resultante de la bacteriemia, más comúnmente de pequeños furúnculos y lesiones de la piel.

Es el origen más frecuente en niños y representa el $80 \%$ de los casos, afectando más comúnmente al hueso metafisario, directa o por contigüidad: es la osteomielitis causada por la inoculación del hueso de una fuente infecciosa adyacente, como sucede en fracturas abiertas, cirugía ósea y propagación contigua a través de defectos de tejidos blandos como úlceras por presión (16).

La etiología suele ser polimicrobiana. Asociada a insuficiencia vascular y neuropatía: como sucede en personas diabéticas, suele afectar los huesos del pie por pequeños traumatismos.

Se realiza una revisión sistemática que permite valorar las bibliografías más recientes del diagnóstico de osteomielitis hematógena aguda en niños, con el objetivo de profundizar y actualizar a los profesionales de la salud, sobre la importancia de identificar las características clínicas y realizar un diagnóstico oportuno para implementar de forma temprana el tratamiento.

\section{MÉTODO}

Se realiza una revisión de artículos y de estudios científicos relevantes, que den validez a lo planteado en el objeto de esta investigación y como criterio de inclusión, aquellos artículos publicados entre los años 
2010-2020, en idiomas: inglés y español. Tales como Medical Literature Analysis and Retrieval System Online (MEDLINE/PUBMED), Cochrane Database (COCHRANE DATABASE), Literatura Latino-Americana y del Caribe en Ciencias de la Salud (LILACS/BIREME), Cumulative Index to Nursing and Allied Health Literature (CINAHL), Web of Science (WEB OF SCIENCE) y Scientific Electronic Library Online (SciELO).

\section{EPIDEMIOLOGÍA}

La osteomielitis aguda hematógena es una enfermedad que afecta a niños previamente sanos. La incidencia de osteomielitis es aproximadamente 8 en cada 100000 niños por año, donde se observa más comúnmente en países de bajos recursos, además de ser 2 veces más frecuente en niños que en niñas. Un $50 \%$ de los casos ocurren en niños menores de 5 años, con un pico de mayor incidencia al año de edad. Frecuentemente, es una lesión solitaria, sin embargo, en neonatos se puede observar multifocal en el $22 \%$ de los casos. La osteomielitis concurrente con artritis séptica se ha reportado en un rango entre $3-33 \%$ (18).

\section{ETIOLOGÍA}

Las bacterias son los microorganismos más frecuentes en osteomielitis, cuando estos microorganismos entran al torrente sanguíneo se alojan en lugares donde el flujo es abundante y lento, principalmente en la metáfisis de los huesos largos como fémur y tibia alrededor de las rodillas (8).

En niños la fuente de la bacteriemia que conduce a osteomielitis hematógena aguda, por lo general no es clínicamente evidente, lo que sugiere que la colonización en las membranas mucosas del tracto respiratorio o a través de la piel, es el portal de entrada más probable. Las bacterias que causan osteomielitis aguda en niños son colonizadores comunes del tracto respiratorio superior, incluidos Staphylococcus aureus (S. aureus), Kingella kingae (K. kingae), Streptococcus pneumoniae (S. pneumoniae) y Streptococcus pyogenes (19).

El $S$. aureus es el agente etiológico más frecuente en todos los grupos de edad, causando al menos el $90 \%$ de las infecciones, es seguido por la $K$. kingae, $S$. pneumoniae y Pseudomona aeruginosa, esta última relacionada con heridas punzantes en el pie. La Salmonella spp y Neumococos spp, también pueden ser causa de osteomielitis en niños con anemia falciforme $(7,6,8)$.

En neonatos los patógenos que ocasionan osteomielitis son estreptococos del grupo B, Escherichia coli y estreptococos del grupo A. (8) Las infecciones por hongos suelen suceder por enfermedad multisistémica diseminada, mientras que las infecciones víricas primarias de los huesos y articulaciones son infrecuentes (6).

\section{MANIFESTACIONES CLÍNICAS}

Los niños con osteomielitis hematógena aguda generalmente tienen síntomas de 3 a 4 días antes de la presentación. Presentan fiebre, dolor localizado, hinchazón y rara vez eritema alrededor de un hueso largo, rango de movimiento limitado y cojera o negativa a soportar peso o usar una extremidad (pseudoparálisis) (20).

La osteomielitis hematógena aguda tiene dos presentaciones clínicas distintas, que divide al paciente de acuerdo con la presencia o no de fiebre. El grupo de riesgo es el lactante febril que presenta síntomas 
inflamatorios sistémicos y signos típicos de septicemia.

El segundo cuadro clínico involucra al niño que puede ser afebril o tener fiebre baja y que demuestra una progresión más gradual de síntomas y signos localizados en el área de infección ósea. Se manifiesta como dolor y sensibilidad en el sitio de infección que puede empeorar con el movimiento y el peso (20).

En general, los signos distintivos de la osteomielitis, independientemente de la presencia de fiebre o signos inflamatorios sistémicos, son el dolor localizado y la función disminuida. Esto debido a que el hueso es un espacio cerrado rígido y el edema precoz del proceso inflamatorio produce un aumento brusco de la presión íntráósea, que explica el síntoma del dolor local intenso y constante. La mayoría de los casos de osteomielitis hematógena aguda involucran los extremos de los huesos largos, por que justifica que sea el área de máxima sensibilidad y dolor (6).

La osteomielitis neonatal, especialmente la que ocurre en el primer mes, es también más probable que sea multifocal que la osteomielitis que ocurre en niños mayores y se presenta más a menudo como septicemia en un paciente crítico (9). La osteomielitis pélvica es difícil de diagnosticar, la mejor herramienta diagnóstica es un alto grado de sospecha por parte del examinador. En la mayoría de los casos el dolor se refiere frecuentemente a estructuras adyacentes como cadera, muslo anterior o posterior y abdomen inferior; también hay diminución de la función al movimiento pélvico, al cargar peso o al caminar (9).

\section{DIAGNÓSTICO}

El diagnóstico de osteomielitis inicia con la sospecha clínica, por esto es importante realizar una historia clínica y un examen físico completo. Conjuntamente, los exámenes de laboratorio y los estudios de imágenes son métodos de apoyo para orientar el diagnóstico.

El diagnostico de esta patología requiere realizar una historia clínica adecuada, conocer datos generales del paciente entre ellos edad, actividad laboral, actividades deportivas, antecedentes patológicos, antecedente de traumatismo, nivel de discapacidad, limitación funcional, hueso afectado, tiempo de evolución, características del dolor, síntomas asociados (16).

Se debe sospechar osteomielitis aguda en pacientes con bacteriemia y clínica compatible sobre vértebras, huesos largos, prótesis de huesos y articulaciones, y en casos de fracturas abiertas o cirugía ortopédica reciente (17).

Los estudios de imágenes diagnósticas más comunes son la radiografía convencional, ultrasonido, tomografía axial computarizada (TAC), resonancia magnética (MR) y gammagrafía ósea.

\section{ANAMNESIS}

Es importante preguntar la edad, si realiza actividades deportivas, antecedentes personales patológicos y de traumatismo, si existe alguna limitación funcional, el tiempo de evolución, característica del dolor y si hay síntomas asociados.

\section{EXPLORACIÓN FÍSICA}

Al realizar el examen físico; hay dolor a la palpación de la región afectada, edema, rubor, aumento del calor local, secreción local, fistulas, limitación del movimiento de la extremidad afectada, las articulaciones del miembro comprometido se mantienen en 
flexión y hay resistencia al movimiento pasivo (10).

\section{ESTUDIOS DE LABORATORIO}

Entre los hallazgos de las pruebas de laboratorio se pueden encontrar elevación en la velocidad de eritrosedimentación (VES), es muy sensible pero poco específica, pues se normaliza a las 3-4 semanas en casos de osteomielitis no complicada y en un $25 \%$ de los casos no presenta incremento en fases iníciales. Está elevada en el $80-90 \%$ de los casos y el pico máximo se alcanza entre 3-5 días (11).

La proteína $\mathrm{C}$ reactiva se eleva en las primeras 8 horas, alcanza el valor máximo a los 2 días y se normaliza a la semana de haber iniciado el tratamiento, es útil para el seguimiento y para diferenciar formas complicadas. Está elevada en el $98 \%$ de los casos (10,11). Ninguno de estos dos reactantes de fase aguda son específicos para el diagnóstico de osteomielitis, ambas de terminaciones deben interpretarse en el contexto de los signos y síntomas compatibles con la osteomielitis.

\section{Hemocultivo}

Ante toda sospecha de osteomielitis aguda, deben obtenerse hemocultivos antes de iniciar antibioticoterapia. Un hemocultivo positivo puede obviar la necesidad de una biopsia ósea, si existe evidencia clínica y radiológica compatible con osteomielitis.

Los hemocultivos son positivos entre el 20 y el $50 \%$ de los casos de osteomielitis aguda. En este tipo de infección, si los cultivos son negativos o urge iniciar el tratamiento, se debería realizar biopsia ósea (10).

\section{RADIOGRAFÍA}

La radiografía simple es un método económico y fácil de realizar, sin embargo, es una técnica con baja especificidad comparada con otras.

Es el estudio de valoración inicial en pacientes con sospecha de osteomielitis, no obstante, es un procedimiento de detección tardío, pues los cambios de destrucción ósea solo pueden ser evidenciados 7-14 días del inicio de la sintomatología (10).

También se pueden observar signos indirectos como el aumento de partes blandas y/o atenuación de las líneas grasas situadas entre los músculos.

Los signos específicos de reacción perióstica tardan en ser visibles aproximadamente 7 días, cuando cerca del $50 \%$ del contenido mineral óseo se ha perdido. Los signos específicos son: elevación del periostio, formación de hueso nuevo, destrucción ósea, osteopenia y pérdida de la arquitectura trabecular (11).

\section{ULTRASONIDO}

Es una técnica rápida, que no utiliza radiación ionizante, es poco invasivo y ofrece imágenes en tiempo real. Igualmente puede detectar características de la osteomielitis varios días antes de lo que lo hacen las radiografías convencionales.

El valor del ultrasonido en la osteomielitis aguda es inversamente proporcional a la edad del paciente.

En los infantes, la fase temprana de la osteomielitis es marcada inicialmente por la inflamación edematosa de los tejidos blandos; ésta es seguida más tarde por un aspecto de colección líquida subperióstica fina (10).

Además, permite identificar abscesos de tejidos blandos, cuerpos extraños o fístulas, y proporciona una guía para la aspiración o biopsia $(6,10)$. 


\section{TOMOGRAFÍA AXIAL COMPUTARIZADA}

La TAC ofrece excelentes reconstrucciones multiplanares. Su utilidad radica, cuando se presenta un resultado de radiografía convencional sin alteraciones y el paciente tiene clínica compatible con osteomielitis.

La TAC puede evidenciar ciertas alteraciones en la estructura ósea o de los tejidos blandos adyacentes, por lo que puede disminuir los casos de falsos negativos registrados en la radiografía convencional. Igualmente, provee de un buen detalle anatómico y distinción entre procesos óseos infecciosos o no infecciosos (6). Es más adecuada para detectar secuestros, trayectos y abscesos de tejidos blandos; sin embargo, es la menos útil para valorar la patología en cuestión. Puede ser útil como guía para aspiraciones percutáneas, subperiósticas y secreciones de tejidos blandos (11).

Este estudio tiene un papel menor en los casos pediátricos debido a su alta exposición a la radiación y la necesidad de anestesia.

La TAC tiene indicaciones en aquellos cuadros clínicos que se manifiestan con dolor y alteraciones en la prueba de imagen, ya que se debe considerar como parte del diagnóstico diferencial de osteomielitis, los traumatismos, enfermedades malignas, debut de artritis reumatoide juvenil e infarto óseo en pacientes con anemia de células falciformes (11).

\section{RESONANCIA MAGNÉTICA}

La RM es muy sensible para la detección de la osteomielitis del día 3 al 5 posterior a la infección, la sensibilidad en osteomielitis varía entre 82 y $100 \%$ y la especificidad entre 75 y $96 \%$ (12).
Además, aporta un detalle anatómico preciso del pus subperióstico y de la acumulación de restos purulentos en la médula ósea y en la metáfisis, para una posible intervención quirúrgica. Permite la detección precoz de la osteomielitis y la evaluación de la extensión del tejido desvitalizado.

Se considera la técnica de imagen más útil para el diagnóstico de osteomielitis, debido a su capacidad para demostrar los cambios en el contenido de agua de la médula ósea. Además, aporta información sobre celulitis asociada, trayectos fistulosos y abscesos. (1).

La RM permite definir la localización del proceso infeccioso y su extensión espacial, en casos de osteomielitis que comprometen vértebras o esqueleto pelviano $(6,10)$.

Las limitaciones más importantes son que se necesita anestesia en niños pequeños, no puede utilizarse en pacientes portadores de dispositivos intracavitarios 0 material protésico metálico y no diferencia infección de neoplasia (11).

\section{GAMMAGRAFÍA ÓSEA}

Es la técnica más utilizada en Medicina Nuclear para obtener imágenes del sistema musculo esquelético. Tiene una sensibilidad que varía entre 73 y $100 \%$, mientras que la especificidad no es muy alta, ya que puede haber captación en otros procesos. Permite la detección de osteomielitis en más del $87 \%$ de los casos, en las primeras 48 a 72 horas en las que la radiología simple puede ser normal (16).

En caso de osteomielitis se detecta una hipercaptación de la zona afectada por existir a ese nivel una mayor perfusión, mecanismos activos de inflamación local e hipermetabolismo óseo. En algunas ocasiones, si la inflamación es muy 
importante y compromete el aporte vascular, la gammagrafía ósea puede dar un falso negativo, observándose como una "imagen fría" al no captar el isótopo (11).

Hay que tener en cuenta que puede dar resultados falsamente positivos en enfermedades que no son osteomielitis pero que cursan con hiperactividad osteclástica, como son fracturas, tumores, traumatismos, lesiones postquirúrgicas, infecciones profundas de partes blandas y artritis (11).

En la gammagrafía ósea con tecnecio 99 (Tc99) se observa un aumento focal de la captación del marcador en áreas con mayor vascularización y actividad osteoblástica del hueso. Si esta puede ser negativa en las primeras 48 horas por la existencia de zonas de infarto o isquemia (11). Si la gammagrafía con Tc99 no es definitiva, se recomienda realizar gammagrafía con galio-67 o con leucocitos marcados $\ln 111$ (11).

Entre las ventajas se encuentran que solo en algunos casos es necesaria la sedación, tiene un costo inferior comparada con otros estudios de imágenes y la capacidad para detectar focos múltiples $(6,10)$.

Las limitaciones de esta técnica son la elevada radiación, la menor sensibilidad para las infecciones de columna y en osteomielitis neonatal no es útil debido a la escasa mineralización del hueso (15).

\section{GRADOS DE SEGURIDAD DIAGNÓSTICA}

Existen varios grados de seguridad diagnóstica los cuales son (15):

- Osteomielitis hematógena aguda firme: la presencia de polimorfonucleares en la biopsia, con cultivo y tinción de Gram positivos.
- Osteomielitis hematógena aguda probable: manifestaciones clínicas, estudios de laboratorio, radiografía sugestiva y hemocultivos positivos $y$ osteomielitis hematógena.

- Osteomielitis hematógena aguda posible: respuesta al tratamiento con antibióticos en pacientes con manifestaciones clínicas, estudios de laboratorio y radiografía sugerente.

\section{CONCLUSIONES}

El microorganismo $S$. aureus sigue siendo el primer agente causal de las infecciones osteoarticulares. Sin embargo, se debe valorar otras posibles etiologías dependiendo de la edad del paciente. El tratamiento oportuno es lo que asegura una evolución médica satisfactoria y una disminución del riesgo de complicaciones.

El diagnóstico de osteomielitis se realiza en conjunto, con manifestaciones clínicas, imágenes y laboratorios como la VES y PCR; siendo mucho mejor esta última para el seguimiento de esta patología.

Las técnicas de imágenes tienen ventajas y Limitaciones dependiendo del método a utilizar y la localización, como la radiografía, la cual es el estudio de valoración inicial; sin embargo, los cambios en el tejido óseo son tardíos por lo que se prefiere usar técnicas más sensibles como la gammagrafía y la RM, siendo la RM la técnica más específica para el diagnóstico de osteomielitis aguda, es ideal para el estudio de osteomielitis vertebral y de esqueleto pelviano.

Los autores declaran no tener conflicto de interés. 


\section{REFERENCIAS}

1. Rojas $M$ Vargas $P$. Osteomielitis Aguda características clínicas, radiológicas y de laboratorio. Revista Médica de Costa Rica y Centroamérica LXXII, 2015, volumen: (615): 347354.

2. Cueteo A Morán E. Osteomielitis. Criterios Actuales Importancia para el Estomatólogo. Rev Cubana Estomatol, 2001, volumen: 38(1): 52-66.

3. Álvarez A Baesso E Casanova C García Y. Osteomielitis en el niño. Estudio de tres años. Revista Archivo Médico de Camagüey, 2004, volumen: (8):3.

4. Pääkkönen M Peltola $H$. Acute Osteomylitis in Children. The New England Journal of Medicine, 2014, volumen: (370): 352 -360.

5. Abood A Krkovic M Moore E Norrish A Taki H. Chronic long bone osteomyelitis: diagnosis, management and current trends. British Journal of Hospital Medicine, 2016, volumen: 77(10).

6. Gómez S Sosa C. Una visión actualizada sobre factores de riesgo y complicaciones de la osteomielitis pediátrica. Revista Cubana de Pediatría, 2016, volumen: 88(4).

7. Bruce R. Trastornos y lesiones del sistema musculoesquelético ,3 ed. Elsevier; 2001.

8. Kliegman R Stanton B Geme J Schor N. Nelson. Tratado de pediatría, 20 ed. Elsevier; 2016.

9. Conrad D. Acute Hematogenous Osteomyelitis. Pediatrics in Review, 2013, volumen: 31(464).

10. Morales D, Ugalde C. Osteomielitis. Med. leg. Costa Rica, 2014, volumen: (31):94-102.

11. Blazquez $M$ Brito $E$ Jimenez J Ruiz J. Osteomielitis jornadas canarias de traumatología y cirugía ortopédica, 2010, volumen: (24):148154.

12. Agurto $P$ Astudillo $C$ Díaz J. Evaluación por Imágenes de Infecciones en el Sistema Musculoesquelético. Revista HCUCh, 2006, volumen (17): 297 - 305.

13. Rico J. Osteomielitis hematógena aguda: mito o realidad. Rev Med Hondur, 2013, volumen: 81(24):108-115.

14. Accadbled F, Ilharreborde B, Labbé J, Lepage B, Thévenin-Lemoine $\mathrm{C}$, Vial J. MRI of acute osteomyelitis in long bones of children: Pathophysiologystudy. Orthopaedics \& Traumatology: Surgery \& Research, 2016.

15. Jiménez D Soto J. Infecciones Óseas Primarias, Osteomielitis agudas y crónicas. Infecciones específicas. Revista Clínica de la Escuela de Medicina.
16. Freire, Luis Francisco Llerena, et al. Osteomielitis: abordaje diagnóstico terapéutico. Archivos Venezolanos de Farmacologia y Terapéutica 38.1 (2019): 53-62

17. Rojas Solano María Jesús, Badilla García Jenny. Osteomielitis Aguda: Características Clínicas, Radiológicas y de Laboratorio. Medicina Legal de Costa Rica.2018.54-61

18. Yeo, A. y Ramachandran, M. (2014). Acute haematogenous osteomyelitis in children. BMJ, 348(66), 1-8.

19. Nicole Le Saux. Diagnosis and management of acute osteoarticular infections in children. Paediatrics \& Child Health, 2018, 336-343.

20. Thakolkaran N, Shetty AK. Acute Hematogenous Osteomyelitis in Children. Ochsner Journal. 2019 ,116-122. 